\title{
DUPLA MATERNIDADE NO INSTAGRAM: ENTRE FOTOS, ATIVISMO E PARENTESCO
}

\author{
Anna Carolina Horstmann Amorin'
}

RESUMO: Este trabalho busca apresentar reflexões sobre a internet enquanto um espaço frutífero para a formação de redes de relações específicas que produzem, de modo acentuado, impactos sobre a formação de identidades de mulheres lésbicas e sobre processos relacionados à construção de maternidades partilhadas por casais de mulheres cisgêneras não heterossexuais. Para tal, foram elencadas e seguidas três hashtags que tocam diretamente no tema das maternidades de mulheres lésbicas e que são utilizadas na rede social Instagram, são elas: \#duplamaternidade, \#mãeslésbicas e \#maternidadelésbica. Através das postagens de fotos com tais legendas observei como a rede social tem sido utilizada como ferramenta para movimentação social em torno da possibilidade real de mulheres lésbicas construírem projetos familiares e de filiação. Neste sentido, não se pode deixar de falar que estas postagens referenciam práticas familiares e paretalidades que contribuem para um estremecimento de fronteiras excessivamente rígidas e fixas no tocante as formas familiares, demonstrando que a norma heterocentrada de família é possível de ser questionada, ganhando relevo neste cenário virtual, não por isso menos real, a construção política de identidades e maternidades. O universo das redes sociais, constitui desta forma, importante espaço de movimentação e ativismo em prol da lesboparentalidade.

Palavras-chave: Parentalidade. Instagram. Ativismo. Maternidades lésbicas.

\section{INTRODUÇÃO: ENCONTRANDO POSTAGENS NO INSTAGRAM}

Este trabalho busca apresentar reflexões sobre a internet enquanto um espaço frutífero para a formação de redes sociais de relações online que produzem, de modo acentuado, impactos sobre a formação de identidades de mulheres lésbicas e sobre processos relacionados à construção de maternidades partilhadas por casais de mulheres cisgêneras não heterossexuais.

Destaco que o interesse desta reflexão tangencia uma pesquisa maior que se dedica a pensar as maternidades lésbicas propiciadas por técnicas de reprodução assistida. Em busca de interlocutoras para tal pesquisa é que entrei em contato com o universo de discussões online a respeito das maternidades lésbicas. Foi ainda quando tecia minha dissertação de mestrado que me aproximei de diferentes blogs que versavam sobre a conjugação entre maternidade e lesbianidade. Nestes blogs apareciam as mais variadas discussões, incluindo informações sobre acesso a tecnologias reprodutivas, preços das consultas, indicações de melhores clínicas e tratamentos, temas de meu interesse à época. Hoje, mais de seis anos passados desde minha primeira aventura no campo do ciberativismo

$1 \quad$ Professora de Antropologia na UEMS-Unidade Amambai. 
relacionado a questões de parentesco, o uso da internet como ferramenta para debates, busca por informação e trocas de experiências não é mais restrito ao universo dos blogs. As discussões sobre maternidade e família adentraram outras plataformas virtuais e ganharam espaço em diferentes mídias sociais. O Facebook foi um dos espaços conquistados por tais debates e existem variados grupos sobre homoparentalidade e famílias LGBT nesta rede social. Há, vale citar, toda uma rede de articulações online que visa promover o encontro entre doadores de sêmen e casais de mulheres lésbicas que ambicionam a maternidade através de técnicas de inseminação caseira, como bem demonstra o trabalho de Mariana Gonçalves Felipe (2019). Entretanto, a interessante movimentação online em prol do produzir famílias nos grupos que correlacionam doadores de sêmens e mães tentantes não é o foco deste artigo. Meu interesse aqui recai especificamente sobre o uso que diferentes mulheres lésbicas mães têm dado para a rede social Instagram, onde circulam fotos, debates e informações que, para além de oportunizarem maternidades, visam o reconhecimento da conjugação entre lesbianidade e maternidade no contexto social brasileiro enquanto uma realidade de parentesco.

O ciberativismo pode ser entendido dentro do campo de pesquisa sobre movimentos sociais e cibercultura e para alguns autores seu aparecimento chega a coincidir com o aparecimento da internet, como bem exemplifica araújo:

Os reflexos do crescimento da internet, como expressão maior do novo paradigma societal, manifestam-se nas mudanças de práticas sociais como as novas formas de mobilização possibilitadas pela rede. O estudo do que se costuma chamar de ativismo em rede, ou ciberativismo, compreende uma demanda científica latente, abordada frequentemente nos estudos em cibercultura. (araújo, 2011, p. 02)

Aponto, nesta pesquisa, especialmente para a existência de um universo online marcado pelo ciberativismo de mães lésbicas que relatam suas experiências de busca pela maternidade conjunta, partilham dúvidas e exibem suas famílias com muito orgulho em fotos e postagens. Especificamente, analiso alguns elementos constantes nas postagens que nos fazem compreender como se tem produzido maternidades de mulheres lésbicas no Brasil e quais as principais questões sociais e políticas envoltas nesta configuração de parentesco quando ela se torna pública e publicizada em redes sociais. Parto, portanto, da análise das postagens realizadas no Instagram sob a rubrica das três hashtags: \#duplamaternidade, \#mãeslésbicas e \#maternidadelésbica para pensar de que modo este universo online configura-se, para além de um lugar de fala individual, como uma rede de articulações políticas e ativista em prol das famílias formadas por duas mulheres, das dupla maternidades e dos direitos de pessoas e casais homossexuais. Destaco que dupla maternidade é uma categoria êmica presente em reportagens brasileiras que fazem referência ao ganho do reconhecimento legal das duas maternidades partilhadas pelo casal de mulheres lésbicas, analisadas por mim em outro momento, e também utilizada pelos próprios casais no Instagram na forma \#duplamaternidade. A noção de dupla maternidade alude um processo criativo no qual se produzem duas maternidades conjuntas. Duas maternidades que possam ter o mesmo reconhecimento e o mesmo sentido apregoado à maternidade para as duas partes do casal. Aqui se evidencia um processo que não é simples ou rápido, mas que se espalha ao longo de um percurso que os casais trilham para elaborar e ver reconhecida a dupla maternidade. 
Não sendo uma relação de parentesco evidente, já que dispensa a noção naturalizada da família como aquela que possui pai, mãe e filhos em favor de uma compreensão da família como formada por duas mães, a dupla maternidade tem de estar em constante construção e afirmação ou validação. Interessa, portanto compreender quais os caminhos e elementos que estabelecem e contam para a produção da dupla maternidade como uma realidade de parentesco. Assim, antes de ser pensada apenas como uma categoria, a dupla maternidade é aqui elaborada enquanto uma pergunta, um fazer: como se constrói a dupla maternidade e qual o lugar da internet neste processo?

\section{LESBIANIDADES, CONJUGALIDADES E PARENTALIDADES NA INTERNET}

Sendo o campo da homoconjugalidade e da homoparentalidade de casais de mulheres recheado de relações, sentidos e práticas complexas, elejo como suportes metodológicos a pesquisa bibliográfica sobre o tema das famílias homoparentais na antropologia, bem como o recurso ao método etnográfico. Destaco, que a pesquisa de campo realizou-se na internet, através de uma "etnografia virtual" no Instagram.

É mister notar, conforme propõe Mário Guimarães Jr (2000) em um artigo sobre as ciências sociais e as pesquisas no ciberespaço, a importância de pensarmos a virtualidade não enquanto uma "não realidade". Guimarães indica que o virtual não se opõem ao real, mas que este complementa e ainda transforma a realidade ao subvertê-la em seus limites espaço/temporais.

O virtual, não se opondo ao real constitui uma dimensão singular da realidade. Já segundo Jean Segata (2008) a antropologia está preocupada, para além de discussões sobre o que é mais ou menos real, melhor ou pior, como a vida das pessoas no ciberespaço e o ciberespaço na vida das pessoas, não como entidades separadas, mas como constructo comum e cotidiano. Segata destaca ainda:

Destarte, é interessante pontuar que, apesar de nas últimas décadas, a antropologia ter, aparentemente, se subdividido multiplamente em pequenas porções especializadas em certos campos e objetos, com a criação de "antropologias da..., do..., ou de...", quando falamos em antropologia no ciberespaço, não estamos reivindicando mais uma especialidade antropológica, que tal como outras tantas é cada vez mais especializada, se apoia cada vez mais em disciplinas irmãs, como a história, a psicologia, a sociologia, ou a filosofia, para darem conta de seus específicos objetos de estudo, terminando por fazer da antropologia como um todo, uma espécie de Torre de Babel, onde antropólogos falam idiomas completamente diferentes. O ciberespaço, aqui, é compreendido não simplesmente como um objeto de estudo antropológico, mas como um campo antropológico com objetos das mais diversas naturezas, tais os de "quaisquer antropologias". Como campo, certamente há exigências teórico-metodológicas específicas, mas elas dialogam com a antropologia como um todo - não são conceitos específicos, com metodologias específicas de "uma antropologia específica. Em suma, tal o que de maneira geral se faz em outros campos de investigação antropológica, neste, o ciberespaço, também fazemos etnografias (SEGATA, 2008, s/p.)

Neste sentido, analiso as postagens realizadas por mães e futuras mães lésbicas na internet enquanto um movimento de militância e ativismo online. Este movimento forja uma coletividade 
virtual de sentidos partilhados a respeito do que é, ou pode ser, a dupla maternidade. Assim, a pesquisa etnográfica compõe-se de um emaranhado de postagens virtuais que se encontram agrupadas abaixo de uma mesma chamada, ou hashtag, sobre maternidades lésbicas na rede social em questão. $\mathrm{O}$ uso de hashtags na internet é bastante recorrente e visa agrupar postagens variadas e de diferentes usuários que tocam o mesmo tema. Assim, ao publicar uma foto em seu perfil, cada usuário do Instagram pode utilizar em sua legenda uma hashtag que a vinculará a um universo mais amplo de todas as demais fotos publicadas utilizando e marcadas com a mesma hashtag. Deste modo, essas publicações, longe de serem específicas e fechadas em perfis individuais de mães, agrupam-se de modo coletivo em um quadro geral de postagens correlacionadas que nos permitem conceituar esse movimento de postar fotos indexando certas hashtags enquanto ciberativismo, já que as fotos e palavras ou legendas escolhidas para cada postagem revelam e reverberam enquanto marcadores de um posicionamento e luta política partilhado por várias outras mães. É neste sentido que este trabalho se propõe a pensar as relações estabelecidas e construídas através da internet, demonstrando como este circuito online faz conversar escritos, pessoas e engajamentos comuns.

Através das análises de fotos e legendas postadas no Instagram se tornam evidentes alguns marcadores importantes do fazer família e produzir dupla maternidade no contexto brasileiro atual. Todavia, antes de abordar especificamente o conteúdo destas postagens, se faz necessária uma breve revisão teórica a respeito das maternidades lésbicas e parentesco na Antropologia e nos estudos feministas.

\section{BREVE REVISÃO TEÓRICA SOBRE O CAMPO DAS DUPLA MATERNIDADES}

Pensando nas tramas que envolvem o estudo das maternidades lésbicas, me debruço sobre um arcabouço teórico específico que perpassa os estudos sobre parentesco, homossexualidade, lesbianidade e família e que desembocam na presente reflexão sobre as mobilizações virtuais como instâncias de militância política de grande alcance e sucesso.

Os estudos teóricos e metodológicos sobre parentesco na antropologia fazem parte da história da disciplina. Entretanto, a antropóloga Cláudia Fonseca aponta que este campo de estudo esteve por certo tempo (anos 70/80) em declínio, sendo praticamente esquecido após os ferrenhos questionamentos políticos e epistemológicos tecidos por diferentes antropólogas e antropólogas que denunciavam o androcentrismo e heteronormatividade presentes nas análises clássicas.

Concomitante a estes questionamentos dos trabalhos clássicos sobre parentesco no seio da Antropologia, não se pode deixar de reconhecer que as antropólogas feministas já vinham na esteira da rejeição da noção de mulher universal e do florescimento dos estudos de gênero, "desnaturalizando" tudo que era tido como natural, a exemplo das noções biológicas presentes no conceito de parentesco. Deste modo, se durante os anos 1970 e 1980 os estudos sobre parentesco pareciam definhar na disciplina, entre as décadas de 1990 e 2000 novos estudos sobre parentesco ganharam fôlego, grande parte deles influenciados pela teoria feminista, que deu novos contornos a este campo de análise.

É certo, segundo Claudia Fonseca (2003) que estes anos de silêncio nos estudos sobre parentesco nada tiveram de tão silenciosos. A teoria feminista e os estudos de gênero estiveram a todo vapor e em contato direto com a antropologia do parentesco, formando ao longo das últimas décadas novos modos de pensar o parentesco. O próprio David Schneider (1995), referência no 
campo destes estudos, aponta o ressurgimento das discussões sobre parentesco como tema de interessa da antropologia, destacando a importância dos estudos gays e lésbicos para esse reavivamento do campo.

Entretanto, a antropóloga Miriam Grossi (2003) destaca que, apesar de mudanças nas configurações familiares, a maioria dos trabalhos desenvolvidos sobre parentesco até os anos 1970 tomavam o sexo como uma categoria "natural" e valores da sociedade ocidental, como a heterossexualidade naturalizada, se reproduziam. Grossi destaca que é a partir dos anos 1970/1980, com o surgimento da antropologia feminista, como já visto acima, que parte das reflexões sobre parentesco passam a incorporar o recorte de gênero em suas análises. Ainda assim, a autora destaca que poucos antropólogos se debruçaram sobre o lugar das relações entre indivíduos do mesmo sexo nas estruturas de parentesco de diferentes sociedades.

Lembro que tais implicações e considerações sobre o parentesco heterocentrado foram alvos de densas críticas. Contudo, sabemos que a antropologia, bem como outras disciplinas, não segue um caminho linear de desenvolvimento teórico. Apesar dos esforços críticos aos modelos biologizantes do parentesco, que Strathern (1992) chama de modelo reprodutivo, no qual a relações de parentesco seriam simples derivações do encontro naturalmente reprodutivo entre pessoas heterossexuais possuindo corpos sexuados diferentes e complementares, tal concepção ainda vigora entre muitos lugares, da antropologia ao senso comum. Esse modelo naturalizado sustenta a supremacia da relação sexual reprodutiva e das conexões biológicas como fundamento de quem é ou deixa de ser pai/mãe de uma criança. Neste cenário, famílias que constroem relações parentais para além destas premissas obteriam menor legitimidade e reconhecimento enquanto promotoras de relações de parentesco, afinal é a genética que vem dar a verdade sobre a filiação.

É certo que por algum tempo foi tomado como evidente a ideia de que às pessoas homossexuais e aos casais formados por pessoas do mesmo sexo estaria excluída a reprodução, Tal ideário, toma as mulheres lésbicas como cercadas por uma infertilidade voluntária que torna antagônica, por exemplo, a relação entre lesbianidade e maternidade (UZIEL, 2007).

Segundo Lewin (1994), que desenvolveu pesquisas sobre maternidades de mulheres lésbicas, a homossexualidade e a maternidade chegavam a ser uma contradição entre termos em dois sentidos, primeiro porque duas mulheres não tendo relações sexuais com homens não poderiam ter filhos e segundo porque maternidade e lesbianidade compreendiam duas identidades opostas, a primeira altruísta, responsável comprometida e a segunda hedonista, egocêntrica e com uma sexualidade entendida como desviante, contrapontos que também marcam as experiências de paternidade de homens gays, como demonstram os trabalhos de Flávio Luiz Tarnovski (2010; 2011).

Para além da antagônica relação ensejada entre lesbianidade e maternidade como pressuposto da exclusão das uniões homossexuais do campo do parentesco e da filiação, a compreensão de que os laços parentais se formam a partir da reprodução biológica, vale dizer, a partir de um encontro sexual reprodutivo entre homem e mulher, também detém um lugar importante nas compreensões que estabelecem a homossexualidade como a negação da família ou do parentesco. Afinal se entende as uniões mulher/mulher e homem/homem como não sendo passíveis de gerar crianças e assim, não sendo constitutivas de famílias, pelo menos não de famílias 'normais'.

Observamos que a reprodução sexual parece vigorar no cerne da noção ocidental de parentesco, como bem evidenciam muitos autores que pesquisam este tema na antropologia (STRATHERN, 1992; SCHNEIDER, 1980; 1984; CARSTEN, 1995; 2000; 2010). Destarte, as pessoas homossexuais parecem sumariamente excluídas deste domínio. Ainda assim, os avanços tecnológicos e suas 
implicações para o pensamento do parentesco têm construído novas possibilidades reprodutivas propiciando a emergência de "novas figuras de parentesco" (LUNA, 2003). Todavia, destaca-se que as famílias formadas por pessoas do mesmo sexo não são novidades e a literatura antropológica a respeito do tema da parentalidade lésbica, gay e trans entende que há alguns diferentes modos de um casal homossexual exercer a parentalidade. De fato que gays e lésbicas exercendo funções parentais são realidades de longa data e são anteriores ao interesse que as famílias homoparentais parecem despertar atualmente (HAYDEN, 1995).

Como informa Paiva (2007) o advento público da homoconjugalidade e da homoparentalidade ${ }^{2}$ tem assumido, a partir dos anos 1990, relevância na agenda política dos movimentos homossexuais que costumeiramente dedicavam-se mais a expressão de um desejo livre, em contrapartida a ideia de casal associada quase que irremediavelmente a dominação de um modelo heterossexual de relações. Ainda que essa não seja a posição hegemônica dos movimentos LGBT, é importante lembrar que a rusga dentro da militância se deve ao risco de reprodução acrítica da heteronormatividade. Entretanto, é certo que as lutas do movimento homossexual se ampliaram, muito em consequência da AIDS e da visibilidade da maternidade lésbica para o campo dos direitos civis no âmbito das famílias (GROSSI et al.,2007). As relações estáveis entre pessoas do mesmo sexo têm ocasionado o surgimento de outra configuração familiar que tem tido cada vez mais visibilidade, a das maternidades lésbicas.

No Brasil as discussões relativas aos direitos homossexuais ganham um lugar no debate político trazendo à tona questões como o casamento e as uniões estáveis entre pessoas do mesmo sexo. Afigura-se que a visibilidade da conjugalidade homossexual, enquanto uma das modalidades familiares começa a ganhar contornos permitindo que gays e lésbicas deem início a um processo de assumir para si e publicamente uma preocupação sentimental em suas relações amorosas (MELLO, 2005). Rompendo com limites de parentalidade e conjugalidade, exigem não somente o direito à cidadania individual, mas o direito à constituição de uma família. O reconhecimento civil da conjugalidade homossexual, que teve seu primeiro passo alcançado com a aprovação pelo Supremo Tribunal Federal da união estável entre homossexuais no Brasil em 05 de maio de 2011, marca uma etapa importante da incorporação nas práticas jurídicas brasileiras de um modelo ocidental moderno de parentesco que era até recentemente marcado, segundo Grossi (2003), pelo modelo único e hegemônico do casal heterossexual com filhos.

Destaca-se então que os anos 2000 têm sido emblemáticos nas lutas dos homossexuais por direitos. Inúmeros eventos e encontros ocorreram e a temática da parceria civil emergiu como prioridade do movimento lésbico, trazendo à tona a possibilidade de reconhecimento do desejo de maternidade como elemento de mobilizações (GROSSI, 2003). Como analisa Luiz Mello, os homossexuais, através de suas reivindicações por direito à família e filhos,

Integrando-se no rol de sujeitos sociais portadores de demandas que, no mundo ocidental, convencionalmente realizam-se por meio da constituição do casal conjugal e da socialização de crianças - filhos biológicos ou adotivos (MELLO, 2005, p.200).

2 Termo cunhado pelo APGL (Associationdes parentes et futurs parentes gays e lesbiens, situada em Paris) no ano de 1997 referente a uma configuração familiar na qual o pai ou mãe define-se como homossexual. 
Destarte, ao introduzirmos esta discussão evidenciamos situações que precisam ser reconhecidas como fenômeno social típico das sociedades contemporâneas. Aludimos a uma luta política importante que está em cena no mundo todo e que conversa de perto com as dificuldades enfrentadas por todos aqueles que se inserem no bojo de relações conjugais e familiares não hegemônicas e por isso marcadas tantas vezes pelo preconceito, silêncio e dificuldades para a nomeação do casal e de sua relação.

\section{4 \#MATERNIDADELÉSBICA, \#MÃESLÉSBICAS E \#DUPLAMATERNIDADE: ANALISANDO AS POSTAGENS NO INSTAGRAM}

A atualidade está marcada pelos avanços tecnológicos e científicos. Não somente as tecnologias são apropriadas para formulação de famílias diversas, como no caso da utilização de tecnologias reprodutivas por casais de pessoas do mesmo sexo, mas conversam com o tema do parentesco também em outras dimensões. Uma delas se consolida através do uso da internet e das redes sociais. Estamos na era da informação e do conteúdo que nos chega rápido através de celulares que mantemos constantemente conectados. A tecnologia garante a circulação e transmissão de informações e mensagens em tempo recorde e quase não há quem consiga se desvencilhar de e-mails, mensagens e redes sociais que monitoram e dão o tom das comunicações da vida cotidiana. De fato, as tecnologias ocupam um lugar importante na vida social contemporânea e tem peso para ditar comportamentos, sentimentos e mobilizar ações.

Em meio a este cenário de propulsão de plataformas e aplicativos que nos prometem aproximar de quem está distante através do compartilhamento de mensagens, fotografias, notícias e informações pessoais cedemos ao que Piza (2012) chama de "fenômeno instagram". O Instagram é, segundo a autora, um aplicativo gratuito existente desde 2010 e que serve para o compartilhamento de fotos com legendas, que podem conter a localização geográfica e são passíveis de utilização de hashtags que agrupam várias imagens postadas por diferentes pessoas/perfis de Instagram em um grupo único de todas as fotografias postadas no aplicativo e indexadas com a mesma hashtag. A base de interações do Instagram se dá na existência de seguidores, amigos e conhecidos com quem se partilha as fotos postadas.

Entre os usos possíveis destes aplicativos estão aqueles voltados a publicização de eventos, palestras, venda e divulgação de produtos variados. A publicidade alcançada pelo compartilhamento das postagens e pela utilização de hashtags parece proveitosa para empreendimentos que buscam atingir grandes públicos. Todavia, há também a possibilidade de que usuários utilizem o aplicativo de modo mais privativo, mantendo suas contas fechadas para aqueles que não fazem parte da sua lista de seguidores/amigos virtuais.

É no entremeio entre estes dois modos de utilização da rede social que o tema das maternidades lésbicas desponta no Instagram. As postagens analisadas neste artigo foram encontradas através do uso de hashtags, ou seja, foram postadas para tornarem-se públicas e comporem o arsenal de outras postagens sobre o mesmo tema e que levam como legenda as mesmas hashtags. Entretanto, grossa parte destas publicações derivam de perfis pessoais de pessoas e não de empresas ou empreendimentos que buscam publicidade. Há, portanto, um uso estratégico desta rede social nas postagens que aqui tomo como referência para pensar o cenário das lesboparentalidades e o ciberativismo.

Este uso é justamente aquele que busca a visibilidade de assuntos e debates sociais que ainda jazem nas margens das representações sociais comuns, como é o caso das famílias e conjugalidades 
de pessoas lésbicas, gays e trans no Brasil contemporâneo. Assim, percebemos que o tema das famílias homoparentais parece incluir-se nesta seara de assuntos que se espraiam na internet atrás de publicização de longo alcance, mas que não buscam apenas publicidade, procuram por visibilidade. Assim, podemos pensar o compartilhamento de fotografias a respeito de famílias formadas por mulheres lésbicas como ações ativistas que tiram do silêncio e do armário configurações familiares que fogem ao padrão estabelecido da família heterossexual.

Por falar em temas que buscam visibilidade social no plano público, destaco as múltiplas fotografias postadas e agrupadas nas hashtags analisas e que são referentes a casamentos e casais de mulheres. Existem muitas destas fotos, ainda que tais postagens não componham a maiorias das publicações encontradas. Ainda assim, estas imagens figuram com bastante recorrência no conjunto das publicações correlacionadas às hashtags analisadas.

Da recorrência destas imagens podemos considerar a importância do casal como central na construção da família que estas mulheres lésbicas buscam publicizar. No contexto das postagens de casal, a grande maioria traz fotos de casamentos ou imagens do casal feliz, provavelmente em algum momento de comemoração e celebração do amor do casal. Percebemos como o casal que se ama parece ser a folha de rosto das relações familiares construídas e representadas como sólidas, felizes e estáveis. A elaboração destas relações conjugais bem sucedidas destaca uma possibilidade de efetivar a relação conjugal enquanto família, pois que pode materializar o amor, (por vezes compreendido como desviante) em formas compreensíveis e legítimas de relação, vale dizer, em forma de crianças e maternidades. Ao mesmo tempo em que o amor conjugal é sinônimo da produção de crianças e de maternidades, ele também é sustento para afastar noções da homossexualidade como fuga aos padrões estabelecidos que impõe o afastamento do desviante, que fica muitas vezes à margem, sofrendo o peso do estigma e da exclusão. Assim, o casal apaixonado e feliz desponta como construção da conjugalidade publicizada entre mulheres lésbicas no Instagram. Contudo, a necessidade de mostrar quem é o casal e assim comprovar a possibilidade de formulação de uma família normal ou feliz, através de fotos descontraídas em parques ou praias, revela um interesse nestes modos familiares que não estão, ainda, bem esclarecidos/firmados no imaginário social. Afinal, as famílias como costumávamos conhecer parecem em pé de transformação. As transformações no seio da instituição familiar parecem informar uma crise ou como salienta Elizabeth Roudinesco (2003), em meio a deslocamentos dos modelos tradicionais (marcados pelo peso de uma ordem de mundo imutável escondida sobre a aba da autoridade do patriarca) a família parece estar em desordem. É justamente na tentativa de garantir que tudo vai bem com as famílias, ainda que outros formatos apareçam, que pululam fotos de casais de mulheres felizes nas redes sociais.

Atualmente, o que se vê é que a noção de família vem passando por transformações. No seio destas modificações a escolha emerge como fundante de uma maior mobilidade no tecer e desfazer laços familiares. Para a confecção de uma família e mesmo de uma relação, como visto anteriormente, é preciso disponibilidade dos sujeitos e um projeto comum. Aqui me sirvo da noção de projeto proposta por Gilberto Velho (1999). Segundo este autor a noção de projeto vale-se primordialmente da ideia de que em todas as sociedades, mesmo nas mais totalizadoras, há possibilidade de individualização que possibilita a confecção de projetos individuais. Tais projetos são construídos em função de experiências sócio-culturais de um código de vivências e interações interpretadas. Todavia, os projetos precisam ser comunicados e deste modo, não podem constituir um fenômeno puramente subjetivo. Define-se, então, que um projeto se funda na noção de planejamento e cálculo de alguns riscos impostos a certa intenção, vontade ou ideal que deve atentar para 
as intenções individuais bem como se inserir em um universo social que o circunda. A maternidade lésbica, analisadas aqui, se inserem então nesta rubrica de projeto. Um projeto partilhado pelo casal e que sem dúvida insere-se de modo coerente e inteligível em um universo simbólico compartido pelo grupo de indivíduos que as cercam, como observamos nas postagens online.

Assim é que parece que o Instagram se torna arena particularmente interessante para a visibilidade e construção da legitimidade social destes projetos comuns de família. Não se trata unicamente de entender que postar fotos e produzir conteúdos sobre nossas vidas privadas e familiares é uma constante da vida contemporânea, senão que esta atividade, quando relacionada a modos de vida e famílias que ainda se encontram fora da norma, detém um poder político importante. É preciso, como vimos com Gilberto Velho, que projetos sejam partilhados, para que seus sentidos sejam socialmente compartilhados. Ao postar fotos de casamentos e casais apaixonados se constrói o projeto conjugal de filiação. Se compartilha a intenção da família e se institui a busca por filhos como consequência natural do enlace amoro da parelha.

No entanto, nem só do casal se faz uma família e entre imagens e mais imagens de casais felizes, destaca-se também a centralidade de fotos de crianças. Tal presença nas postagens do Instagram revela a centralidade da filiação e da criança (SOUZA, 2005) para a confecção do sentido da família, em consonância com o modelo posto de família nuclear dada pelos pais e filhos. Tal centralidade parece ir na contramão do clássico estudo sobre parentesco gay e lésbico na São Francisco (EUA) do final dos anos 1980, onde Kath Weston (1991) foge da primazia dos vínculos biológicos e consanguíneos para pensar o parentesco e leva a discussão sobre para outro caminho: "Familial ties between persons of the same sex that may be erotic but are not grounded in biology or procreation do not fit any tidy division of kinship into relations of blood and marriage" "(WESTON, 1991, p. 3). A autora demonstra em seu trabalho como gays e lésbicas colocam o acento de suas relações em noções de amizade, afeto e escolha. Estas seriam as bases da conectividade entre as pessoas e o elo das famílias que escolhemos (families we choose). Neste cenário, a escolha, o afeto e as relações de proximidade, suporte emocional e amizade emergem como fatores importantes, pois configuram e sustentam conexão e vínculos de parentesco. Já entre os casais de mulheres lésbicas que postam no Instagram, as crianças parecem elementos fundamentais da configuração da família. Quando falamos nas famílias homoparentais desta pesquisa, ainda que estejamos aludindo a um modelo familiar distinto daquele narrado por Weston onde a amizade e não a reprodução tecia conexões e famílias, também falamos em um idioma de parentesco marcado pela escolha. Se entre os casais heterossexuais é presumido que tenham filhos, a "opção" permite que não os tenham. "Já para os homossexuais, o sentido dessa presunção é que não tenham filhos, fazendo com que a "opção" implique numa ação positiva" e consciente (TARNOVSKI, 2011, p. 2). Mas não é apenas o momento certo que estes casais planejam. Notadamente, decidem sobre os contornos de suas famílias, sobre gravidezes, sobre doadores e sobre quais os elementos dispensáveis ou imprescindíveis para a fabricação das maternidades no plural. Duas mães, é esse construto que importa e se deseja e "Le fait d'élaborer dès le départ ce projet à deux est décisif” (DARIUS; DÉCHAUX, 2016, p. 127) para a construção desta maternidade partilhada. O parentesco se torna uma questão de escolha, de negociação das relações estabelecidas

3 Os laços familiares entre pessoas do mesmo sexo que podem ser eróticos, mas não fundados na biologia ou na procriação, não se enquadram em nenhuma divisão organizada do parentesco como relações de sangue ou casamento (Tradução nossa).

4

O fato de elaborarem desde o início o projeto a dois é decisivo (Tradução nossa). 
e daquelas que se deseja ensejar. A dupla maternidade não acontece como um passo simples, antes ela é construída.

Não obstante, no contexto das famílias de mulheres estudadas aqui através de compartilhamento de fotos no Instagram, o que se aponta não é somente uma transformação da noção de família - agora também formada por casais homossexuais, mas um debate sobre como se constituem as relações de filiação e também de parentesco para além de uma compreensão naturalizada, que nos força a perceber o quanto as famílias são resultado da intencionalidade, já que para as famílias homoparentais a compreensão é a de que a família se faz ao contrário da ideia de que família se tem. Nesta confecção, o lugar da mãe que não possui vínculos biológicos e que não engravida é paradigmático para compreensão dos caminhos intencionais que instauram a dupla maternidade.

Sem o peso da gravidez ou da conexão biológica com o futuro filho, a mulher que não gesta pode ver seu lugar enquanto mãe ameaçado. Assim, observamos nas imagens analisadas que a grande maioria das postagens são de fotografias em que aparecem as duas mães e seus filhos. A constante aparição das duas mulheres juntas ao lado de barrigas grávidas, durante o parto, em chás de bebês ou mesmo antes do nascimento através de imagens de testes de gravidezes positivos, revelam estratégias centradas na consolidação do lugar desta mãe que não engravidou e que, por isso, não tem seu vínculo biológico na construção desta família. A presença dela em todos estes momentos garante a maternidade, já que ela constrói seu espaço através da participação intensiva registrada em foto e tornada pública nos perfis de Instagram - no projeto comum da maternidade partilhada.

No contexto dos casais de mulheres lésbicas, o estar junto e o fazer a criança conjuntamente parece produzir um sentimento de partilha efetiva da maternidade, conforme já apresentado em outras pesquisas (AMORIM, 2018). O cotidiano torna-se relevante, criar um filho juntas e partilhar o dia a dia também produz a relação. Como bem se evidencia, a parentalidade passa de consequência natural de uma relação a uma intenção de tornar-se pai/mãe (TARNOVSKI, 2010) que se coloca em ação através de um projeto construído. Este projeto precisa ser publicizado, precisa ser registrado e compartilhado para afastar questionamentos. Em tempos em que a vida parece cada dia mais midiatizada, o sentido do estar junto na construção do que é a maternidade lésbica também é edificado na postagem e compartilhamento constantes de fotos nas redes sociais. Assim, o entorno do casal vai sedimentando a realidade expressa daquela relação homoconjugal como família e a futura criança vai se "emparentando" das duas mães.

Ao mesmo tempo, ao lado das fotos de casais e crianças, as muitas fotos de barrigas grávidas sozinhas, que também aparecem em grande quantidade entre as postagens analisadas, parecem informar que os casais do mesmo sexo também buscam efetivar suas famílias dentro da simbólica da filiação biológica, do vínculo de sangue e da gravidez. Destaca-se uma interessante agência e intencionalidade destas mulheres que colocam em ação diferentes tecnologias disponíveis para produção de gravidezes e para promoção de seus desejos de filiação, a parte de estarem em relacionamentos homossexuais. As tecnologias produzem relações em uma coreografada articulação entre noções de pertencimento balizadas pela biologia, mas também pelo cotidiano, pelo cuidado e pela proximidade que produz o sentido da maternidade e da família. Apesar de menos frequentes, as barrigas grávidas presentes nas fotografias parecem dar sustento ao parentesco biológico ou de sangue que se busca demonstrar no contexto das maternidades lésbicas no Instagram. É mister notar que a valorização da conexão biológica pretendida com fotografias de barrigas grávidas apresentada nas fotografias compartilhadas, não é qualquer biologia. A conexão biológica em destaque é aquela que 
produz a maternidade da mãe grávida, mas não aquela que poderia construir qualquer paternidade. As gravidezes das fotografias podem ter sido produzidas em clínicas, em relações sexuais hétero com fins reprodutivos ou ainda com auxílio de doadores conhecidos de sêmen, contudo, não são estas etapas da fabricação da criança e das gravidezes que despontam nas imagens das postagens do Instagram. O processo necessário para concretizar a gravidez não parece o mote de atenção, a família consolidada com a chegada de crianças sim. Ainda que a gravidez tenha destaque, não há espaço para uma terceira pessoa e um possível doador ou pai que possa concorrer com a maternidade da mãe que não engravida não aparece nas postagens. Fugindo da noção naturalizada de que uma criança tem um pai e uma mãe, a dupla maternidade apresenta-se como um novo construto fruto do artesanato fino implicado na construção das famílias lesboparentais e o parentesco destaca-se como reflexivo, pois tem que ser construído, como bem evidenciam a superioridade numérica da fotos em que os casais de mulheres aparecem intencionalmente como suporte da filiação. Por tal, são maioria as postagens de fotografias em que as duas mulheres aparecem acariciando a barriga grávida, ou em que os primeiros momentos do nascimento são registrados em fotos que atestam a presença das duas mulheres durante o parto. As conexões biológicas valorizadas na construção das dupla maternidades publicizadas são apenas aquelas dadas em termos de gravidezes e amamentação, momentos que podem ser compartilhados pelas duas mães através da presença registrada de ambas durante o processo ou que podem figurar como momento singular da mãe gestante. Neste processo de consolidar o lugar das duas mulheres na produção intencional e presencial das maternidades partilhadas é que as postagens no Instagram parecem desvelar grande importância.

Como observamos no cenário das famílias homoparentais, o parentesco deixa definitivamente de pertencer a um domínio privado. Ele invade noticiários, debates presidenciais, publicidades e redes sociais. Contudo, diferente das demais esferas públicas que parecem noticiar as lesboparentalidades como curiosidade ou novidade, as redes sociais, tal como o Instagram, despontam como táticas de publicização e visibilidade acionadas pelas próprias mães lésbicas. Usadas como ferramenta, as mídias sociais atestam a partilha da maternidade, a felicidade do casal que aumenta sua família e que disputa reconhecimento para a lesboparentalidade. Parece claro, afinal, que o parentesco é uma arena importante da vida social e as mulheres lésbicas não furtam de disputar seu lugar neste domínio através do ciberativismo.

Não é apenas que o parentesco parece importar nas sociedades ocidentais atuais, senão que ele parece também força motriz de uma transformação social que nos remete às lutas feministas que decorrem dos anos 1970 e que prescrevem a desnaturalização de relações imutabilizadas por pressupostos em natureza. De tal forma, o alargar de sentidos de pressuposições que só faziam referência a um único modelo familiar importa, bem como importa compreender como os casais de mulheres lésbicas estão fazendo isso através das redes sociais, como o Instagram.

As fotos compartilhadas aparecem como produtoras de uma memória familiar e permitem o reconhecimento de uma história partilhada: "A fotografia funciona como suporte para as lembranças e como veículo de memória, permitindo reconstruir, desde o presente, situações vividas ou não vividas" (MASSA, 2016, p.298).

É a fotografia que comprova a relação. A antropóloga Jimena Maria Massa (2016), ao analisar o lugar das fotografias para a composição da relação de parentesco entre netos/netas apropriados na ditadura militar argentina que tiveram suas identidades restituídas e retomaram relação com sua família biológica depois de adultos, explica interessantemente o lugar de destaque que as fotografias ocupam no processo de "tornar-se parente". Tal autora demonstra especialmente como fotografias 
de família servem, por vezes, como comprovações de histórias e vínculos afetivos passados que foram intencionalmente apagados e que agora se busca ativamente reconstituir.

Ao lado das muitas fotografias sobre casamentos, casais e crianças também despontam postagens sobre pronunciamentos a respeito do tema das famílias lesboparentais. Discussões a respeito das certidões de nascimento, debates sobre avanços e impasses políticos que tocam o tema das famílias homoparentais aparecem, em menor quantidade, mas estão presentes, demonstrando uma efetiva movimentação e militância em torno dos temas da família e parentalidade.

\section{CONSIDERAÇÕES FINAIS: FALAR DE FAMÍLIA É MILITÂNCIA?}

Se de um lado as contribuições feministas são de tamanha relevância para o debate sobre parentesco e homoparentalidade, por outro alguns posicionamentos dentro do próprio movimento feminista apontam para tensões no que se refere a uma crítica radical à instituição do casamento e a defesa da igualdade de direitos.

Como nos mostra Miguel Vale de Almeida (2010) alguns "setores do feminismo lésbico subscrevem a noção de que o casamento e a família são instituições que historicamente subordinaram as mulheres e que, sobretudo, o Estado não deveria definir os contornos das relações entre dois adultos" (ALMEIDA, 2010, 2 p.112). A preocupação nestes setores parece gerar em torno do fato do contrato de casamento e a filiação configurarem uma tendência para encaixar gays e lésbicas num modelo heterocentrado de coabitação obrigatória, fidelidade e deveres econômicos. Parece haver uma certa postura de que as famílias, casais e pessoas homossexuais deveriam comportar-se de modo revolucionário ou mesmo crítico às instituições sociais.

Camila Pinheiro Medeiros (2004) aponta que parece haver uma distinção no que tange o posicionamento político da família homoparental e da exposição da lesbianidade daquelas que são e não são vinculadas aos movimentos sociais. Camila afirma que, de modo geral, as mulheres não ligadas aos movimentos sociais ou as não militantes corroboram a lógica do "não precisa ficar falando a toda hora" e assim reivindicam para si e para sua família um lugar de normalidade e adaptação a um meio social homofóbico.

Apesar de haver pouca ou quase nenhuma referência a participação em movimentos sociais organizados nas postagens das mulheres mães lésbicas no Instagram e analisadas neste trabalho, aponto que o compartilhamento de fotografias de famílias lesboparentais podem ser entendidas enquanto militância. Afinal se militância configura ter de "estar falando" reivindico para as postagens realizadas no Instagram a compreensão enquanto um espaço de ativismo e destaco a maternidade como mola propulsora de um engajamento político e identitário em prol do reconhecimento e visibilidade da maternidade lésbica e, por consequência, da própria lesbianidade como possibilidade social.

As postagens no Instagram são realizadas no intuito de comunicar e fazer circular as histórias de vida dessas mulheres, os percursos de uma vida homossexual, a construção de relações conjugais e o desejo pela construção de famílias. Tais postagens virtuais estão recheadas de discussões sobre a construção das maternidades lésbicas e sobre a necessidade de tornar pública a existência destas mulheres, destes casais e dessas famílias, dando suporte para tantas outras mulheres que vivenciam realidades similares.

Se muitas vezes estas mães lésbicas estão ausentes dos movimentos sociais e da militância formal, elas atuam produzindo coletividades virtuais. Suas postagens e o uso estratégico das hashtags 
demonstram a intenção de produzir relações, conexões e discussões partilhadas. As postagens no Instagram são reveladoras no que toca a necessidade de evidenciar a possibilidade real de homossexuais construírem projetos familiares e de filiação.

Neste sentido, percebe-se claramente como e as sociedades mudam e com elas os significados culturais, inclusive aqueles ligados ao que é ou não movime to social e militância. Cabe a nós atentarmos para a necessidade do reconhecimento destes modos de viver e fazer família.

Por fim, podemos destacar que tais postagens ocupam um importante lugar enqua to chave para saída do armário das mães lésbicas e de tantas outras mulheres lésbicas. Configuram-se como "ato primordial de libertação, simultaneamente auto constitutivo do sujeito e politizador da identidade" (ALMEIDA, 2010, p.22) visto que servem como publicização de uma história, de uma experiência e de base para a transformação do desejo em identidades através do encontro com semelhantes. $\mathrm{O}$ encontro com outras famílias possibilita a sua própria aceitação e impele a discussão aberta sobre reconfigurações familiares, sobre a necessidade de adequações jurídicas para estas realidades e nos dão a ver como estão sendo constantemente construídas, remodelas, classificadas e pensadas os modelos estabelecido de parentesco, parentalidade e família. Lembro, que as problematizações sobre gênero, parentesco, família, conjugalidade só apresentam relevância no momento em que casais de lésbicas e gays efetivamente começam a criar crianças e instauram-se transformações nas relações de gênero, nas conjugalidades, nas percepções da sexualidade, nos mecanismos da reprodução humana ou nas noções de propriedade, tutela e responsabilidade das e para com as crianças. Fatos etnograficamente verificáveis através das postagens de fotos no Instagram que cumprem papel de dar visibilidade a estas configurações familiares perante a nossa sociedade que, infelizmente, continua materializando este arranjo familiar em um recorte estigmatizado.

Falar de filhos, família e casamento é, portanto, um caminho de luta, de ativismo e mobilização social. Neste sentido, não se pode deixar de falar que estas public ções virtuais referenciam práticas familiares e parentalidades que contribuem para um estremecimento de fronteiras excessivamenterígidas e fixas que demonstram que os modelos de famílias heterocentradas são passíveis de serem questionados, ganhando relevo neste cenário virtual, não por isso menos real, a construção política das identidades. Constituindo-se, desta forma, importantes espaços de organização e porque não, de militância.

\section{REFERÊNCIAS}

ALMEIDA, Miguel Vale de. O casamento entre pessoas do mesmo sexo. Sobre "gentes remotas e estranhas" numa "sociedade descente". In: Conjugalidades, Parentalidades e identidades Lésbicas, Gays e Travestis. Miriam Grossi, Anna Paula Uziel e Luiz Mello (orgs). Rio de Janeiro: Garamond, 2007.

A chave do armário: homossexualidade, casamento e família. Florianópolis: Editora da UFSC, 2010.

ARAÚJO, Willian Fenandes Ciberativismo: levantamento do estado da arte na pesquisa no Brasil. In:V Simpósio Nacional ABCiber - Dias 16, 17 e 18 de Novembro de 2011 - UDESC/UFSC.

CARSTEN, Janet. The substance of kinship and the heat of the hearth: Feeding, personhood and relatedness among Malays of Pulau Langkawi. American Ethnologist, n. 22 (2), p.223-241, 1995. 
.Cultures of relatedness: New approaches to the study of kinship. Cambridge: Cambridge University Press. 2000.

DARIUS, Mérylis ; DÉCHAUX, Jean-Yves. Les deux mères. Familles homoparentales féminines en France. In: Parenté Contemporaines, Journal des anthropologues, Paris: Association française des Anthropologues, n. 144-145, p. 123-146, 2016.

FELIPE, Mariana Gonçalves. Maternidade lésbica por meio de inseminação caseira: dinâmicas e processos de escolha dos doadores nas redes sociais. Monografia (Bacharelado em Ciências Sociais) da Universidade Federal do Paraná, Curitiba, 2019.

FONSECA, Cláudia. De Afinidades a Coalizões: uma reflexão sobre a "transpolinização" entre gênero e parentesco entre décadas recentes da Antropologia. Ilha Revista de Antropologia. Florianópolis: UFSC, vol.05, n.2, Dez. 2003

Homoparentalidade: novas luzes sobre o parentesco. Revista Estudos Feministas, Florianópolis, v. 16, n. 3, Dec. 2008.

GROSSI, Miriam. Gênero e Parentesco: famílias gays e lésbicas no Brasil. Cadernos Pagu, Campinas, n.21, 2003.

.UZIEL, Anna Paula; MELLO, Luiz. Introdução. Conjugalidades e parentalidades não hegemônicas: um campo em construção. In GROSSI, M.; UZIEL, A. P; MELLO, L.(org). Conjugalidades, parentalidades e identidades lésbicas, gays e travestis. Rio de Janeiro: Garamond, 2007.

GUimarães JUNIOR, Mario. O ciberespaço como Cenário para as Ciências Sociais. Revista Ilha, Florianópolis: UFSC, n.1, dez. 2000.

HAYDEN, Corinne. Gender, genetics and generation: Reformulating biology in lesbian kinship. Cultural Anthropology, v. 10, n. 1, p. 41-6, 1995.

LEWIN, Ellen. Negotiating Lesbian Motherhood: The Dialectics of Resistance and Accommodation. In: GLEMM, N.; CHANG, N.; FORCEY, N. Mothering: Ideology, Experience, and Agency. New York/ London: Routledge, 1994.

LUNA, Naara. Novela e Biotecnologia: os pais de 'O Clone' segundo mulheres em tratamento de infertilidade. In: GROSSI, Miriam; PORTO, Roseli; TAMANINI, Marlene. (orgs.). Novas Tecnologias Reprodutivas Conceptivas: questões e desafios. Brasilia: Letras Livres, 2003, p.53-68.

MASSA, Jimena Maria. "Restituição de identidades" e (re)construção de parentesco em casos de "netos/as apropriados/as" pela ditadura militar argentina. 2016. 390f. Tese (Doutorado em Antropologia Social) - Pós-graduação em Antropologia Social, Centro de Filosofia e Ciências Humanas, Universidade Federal de Santa Catarina, Florianópolis, 2016.

MEDEIROS, Camila Medeiros. Sobre deveres e prazeres: estudos acerca de mulheres que se assumiram lésbicas depois de terem sido mães. Trabalho de conclusão de curso (Bacharelado em Ciências Sociais) apresentado ao Departamento de Ciências Sociais do Centro de Filosofia e Ciências Humanas, Universidade Federald e Santa Catarina, Florianópolis, 2004. 
MELLO, Luiz. Outras famílias: a construção social da conjugalidade homossexual no Brasil. Cadernos Pagu, Campinas, n. 24, jun. 2005.

PAIVA, Antônio Crístian Saraiva. Reserva e Invisibilidade: A construção da Homoconjugalidade numa perspectiva micropolítica. In: Conjugalidades, Parentalidades e identidades Lésbicas, Gays e Travestis. Miriam Grossi, Anna Paula Uziel e Luiz Mello (orgs). Rio de Janeiro: Garamond, 2007.

PIZA, Mariana Vassalo. O fenômeno do Instagram: considerações sob a perspectiva tecnológica. Monografia (bacharelado em Ciências Sociais) Universidade de Brasília, Brasilia, 2012.

ROUDINESCO, Elizabeth. A família em desordem. Rio de Janeiro: Jorge Zahar Editor, 2003. 199 pp.

SCHNEIDER, David. American Kinship: a cultural account. New Jersey: Prentice-Hall, 1980.

A critique of the study of kinship. Ann Arbor: University of Michigan Press. 1984.

SEGATA, Jean. Antropologia no Ciberespaço. Coluna, n 42., 2008. Disponível em http://www.antropologia.com.br/colu/colu42.htm. Acesso em 17 nov. 2019.

SOUZA, Érica R. Necessidade de filhos: Maternidade, família e (homo)sexualidade. Tese de doutorado em Ciências Sociais. Instituto de Filosofia e Ciências Humanas, UNICAMP. Campinas, 2005

STRATHERN, Marilyn. Reproducing the future: essays on anthropology, kinship and the new reproductive technologies. Manchester: Manchester university Press, 1992.

TARNOVSKI, Flavio. Être père et homosexuel dans la France contemporaine. Tese (Doutorado em Antropologia Social) École des Hautes Études en Sciences Sociales. Toulouse, 2010.

. Homoparentalidade à brasileira: paternidade homossexual em contextos relacionais. In: CÁCERES, C.F.; MOGOLLÓN, M.E.; PÉREZ-LUNA, G.; OLIVOS, F. (orgs). Sexualidade, ciudadanía y derechos humanos en América Latina. Lima: IESSDEH, UPCH, 2011, p. 69-75.

UZIEL, Anna Paula. Homossexualidade e adoção. Rio de Janeiro: Garamond, 2007.

VELHO, Gilberto. Projeto, Emoção e Orientação em Sociedades Complexas. In Individualismo e Cultura: Notas para uma Antropologia da Sociedade Complexa. Rio de Janeiro: Jorge Zahar Editor, 1999.

WESTON, Kate. Families We Choose: Lesbians, Gays, Kinship. Columbia University Press, New York, 1991

Sites consultados:

https://www.instagram.com/explore/tags/duplamaternidade/

https://www.instagram.com/explore/tags/maternidadel\%C3\%A9sbica/

https://www.instagram.com/explore/tags/maeslesbicas/ 